ISSN: 0212-0267

DOI: http://dx.doi.org/IO.I420I/hedu20I635191216

\title{
UNAMUNO: LAS FUNCIONES EDUCATIVAS DEL ESTADO. DEL ESTADO DOCENTE AL ESTADO ORGANIZADOR DE LA ENSEÑANZA
}

\section{Unamuno: the educational functions of the State. From a Teaching State to an Education Organizer State}

Emanuel José Maroco dos Santos

Fundão, Portugal

Correo-e: emanuel.ejms.santos@gmail.com

Recepción: 20 de noviembre de 20I4. Envío a informantes: I8 de febrero de 2015.

Fecha de aceptación definitiva: 6 de junio de 2015

RESUMEN: El artículo pretende determinar los fundamentos políticos de la educación propuesta por Unamuno, que, en muchos sentidos, comulga con la posición defendida por los regeneracionistas, en su época histórica, siendo cierto que su postura aporta algunas matizaciones connotativas a raíz de su peculiar concepción de la enseñanza laica, ya que, como es bien sabido, en Unamuno el concepto laico no pierde sentido religioso, al vincularse con la religión católica popular española (Volksgeist).

La democratización de la enseñanza, el estatismo docente y la antipolitización de la enseñanza son los tres principios políticos más característicos de nuestro autor, pese al hecho de que éste se haya desvinculado de su defensa de la «escuela única» después de la aprobación de la Constitución española de I93I, en virtud de su reacción a los artículos 26 y 48.

El presente trabajo, sin olvidar el ambiente cultural de la época, se centra, fundamentalmente, en el pensamiento de Unamuno, procurando determinar la coherencia interna de sus postulados y principios educativos.

Palabras clave: Fundamentos educativos; igualdad; libertad; autonomía; Estado Docente; Estado Mayor de la Enseñanza. 
AвSTRACT: The article aims to determine the political foundations of the education proposed by Unamuno, who, in many ways, agrees with the position defended by the Regenerationist Movement, in its historical time. However, it remains true that his position casts some connotative nuances resulting from his peculiar conception of secular education, since, as known, the secular concept in Unamuno does not lose any religious sense, when bonding with the Spanish popular Catholicism (Volksgeist).

The democratization of education, the statist education and the anti-politization of teaching are the three most distinctive political principles of this author, despite the fact that he detached from his defense of the «common school» after the approval of the Spanish Constitution of I93I, due to his reaction to articles 26 and 48 .

In the light of the cultural atmosphere of the time, the present article focuses primarily on Unamuno's thinking, trying to determine the internal coherence of his postulates and educational principles.

KEY wORDs: Educational foundations; equality; freedom; autonomy; Teaching State; Chief State of Education.

\section{Planteamiento del artículo}

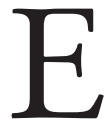

N EL PRESENTE ESTUdio, nos proponemos determinar los fundamentos políticos de la educación propuesta por Unamuno, en cuanto rector de la insigne Universidad de Salamanca. Por motivos teórico-conceptuales, lo hemos dividido en cuatro capítulos. En el primer capítulo, hemos intentado determinar el principio de igualdad como primer fundamento de su teoría educativa, que le exigió la defensa de la democratización de la enseñanza a partir de su extensión a todos los ciudadanos, independientemente de su sexo o estrato social. En el segundo y tercero, nos hemos centrado en el principio de la libertad, que le ha conducido a la afirmación contradictoria del «Estado Docente» y del Estado Organizador de la Enseñanza, antes y después de la Constitución española de 193I.Y en el cuarto capítulo, hemos procurado analizar su peculiar concepción del «Estado Mayor de la Enseñanza», que, en cuanto institución educativa superior e independiente del poder político, permitiría, según su peculiar visión de la educación, la estabilidad y el desarrollo continuo de las políticas educativas.

\section{La democratización de la enseñanza: el sexo y el estrato social}

Creo que acaso fuese un expediente salvador el de suprimir en España todas las Universidades y aun los Institutos, convertirnos a los profesores de unas y otros en maestros de escuela y repartirnos por los pueblos después de que hubiéramos aprendido a enseñar a leer, escribir y contar con sentido. Es más fácil que surjan de por sí, espontáneamente, buenos médicos, ingenieros o artistas de un pueblo de 
UNAMUNO: LAS FUNCIONES EDUCATIVAS DEL ESTADO. DEL ESTADO DOCENTE AL ESTADO ORGANIZADOR DE LA ENSEÑNAZA EMANUEL JOSÉ MAROCO DOS SANTOS

sólida instrucción primaria que no el que un escogido pelotón de especialistas dé cultura a un pueblo que la necesitar.

La democratización de la enseñanza fue una de las grandes propuestas educativas de Unamuno. Para el rector salmantino, todos los ciudadanos, independientemente de su sexo o estrato social, deberían tener acceso a la educación, ya que ésta constituía, y constituye, un derecho universal inherente a todo hombre. Si al día de hoy dicha propuesta parece carecer de significado, en la medida en que todos los Estados occidentales han posibilitado el acceso de todos los ciudadanos a la educación, haciéndola incluso obligatoria hasta una determinada edad, lo cierto es que, en la época de Unamuno, ésta era tan sólo un privilegio de algunos ciudadanos como lo atestigua el hecho de que su España finisecular ostentase dos tercios de analfabetos absolutos. Por ello, cuando se encuadra en su contexto histórico, dicha propuesta es particularmente significativa, ya que expresa la asunción de un ideal humano, ante el cual no cabe, ni puede caber, ningún tipo de concesión. Asimismo, pese al hecho de que dicha propuesta (en cuanto propuesta) carezca de significado en los días de hoy, su defensa por parte de Unamuno tiene por lo menos el enorme mérito de señalarnos que la educación es un derecho universal, que ningún hombre o Estado podrá nunca poner en duda o soslayar.

Muchas fueron las ocasiones en las que Unamuno se refirió a la realidad educativa finisecular española. Empero, por cuestiones metodológicas, vamos a circunscribir nuestros análisis a las conferencias que dio entre los años de 1903 y 1906, ya que fue en dicho periodo cuando Unamuno miró más de cerca las causas y problemas del analfabetismo español. Para el bilbaíno, dos eran los principales problemas de la enseñanza en su época histórica: el primero radicaba en las profundas desigualdades en el reparto de los bienes culturales y el segundo en el extensísimo porcentaje de analfabetos ${ }^{2}$. El hecho de que hubiese una pequeña minoría de ricos en lo que concierne a los bienes culturales y una extensísima mayoría de mendigos de éstos era, a su juicio, un síntoma claro de una sociedad retrasada que apremiaba cambiar. Otro problema, no menos importante, residía en la escasa importancia que las familias de los estratos más bajos de la población concedían a la escuela en cuanto motor de transformación social, ya que, para Unamuno, jamás podrían obtenerse los mismos niveles de cultura e ilustración de los países más ricos y desarrollados si las familias, y quien dice las familias dice la propia sociedad, no concedían ninguna importancia a la formación de los jóvenes alumnos. Fue por ello que, en contra de la mentalidad capitalista, afirmó ante un conjunto de amigos que preferiría dar a sus hijos una buena educación que un extenso capital como herencia ${ }^{3}$. Sin embargo, pese al hecho de que Unamuno percibiese que el mayor obstáculo a la alfabetización de la sociedad finisecular

Unamuno, Miguel: «La pirámide nacional», en O. C., Madrid, Escelicer, I968, vol. 3, p. 689.

Cf., Unamuno, Miguel: Conferencia en el Teatro Cervantes de Málaga, el día 21 de agosto de 1906, en O. C., Madrid, Escelicer, 1971, vol. 9, pp. I87-188.

Cf., Unamuno, Miguel: Conferencia en el circuito literario de Almería, el 30 de agosto de 1903, en O. C., Madrid, Escelicer, 1971, vol. 9, p. I3I. 
española radicaba en la escasa importancia que los padres concedían a la educación de sus hijos, eso no le impidió ver que el Estado tenía un papel fundamental también en el progreso cultural de su país, ya que sin su tutela y amparo la educación de las jóvenes generaciones estaría seriamente comprometida. En las familias y en el Estado radicaba, pues, según Unamuno, la condición de posibilidad de la transformación de la sociedad española. Cabría subrayar tan sólo que si a algo fue reacio Unamuno eso fue sin duda a la enseñanza de talante capitalista, ya que, para el bilbaíno, la escuela no tenía la función de mantener el orden social preestablecido, sino la de extender la cultura a todos los ciudadanos, más allá o más acá de la posición social de cada individuo y de su sexo4. No nos extraña, pues, que Unamuno mantuviese una doble actitud: la de ensalzar las escuelas que acogían alumnos provenientes de todos los estratos sociales ${ }^{5}$ y la de criticar la avaricia intelectual de los eruditos españoles ${ }^{6}$.

(I) Presenta nuestra sociedad, tocante a instrucción y saber, grandes desigualdades, pues junto a unos pocos y muy acaudalados ricos, hay turbas y más turbas de menesterosos [sic] mendigos ellas; hállase la cultura muy mal repartida, y en ella, aún más que en la tierra, el maleficio de los latifundios y dehesas?.

(2) Me fío poco de las estadísticas, pero sé que hay en España muchos analfabetos. Sin embargo, no es el mayor mal a este respecto el número de analfabetos que hay, sino el hecho de los [sic] que saben leer y escribir es como si no lo supieran, pues ni leen ni escriben cosa que lo valga ${ }^{8}$.

La democratización de la enseñanza, esto es, la alfabetización de toda la sociedad española, era, a juicio de Unamuno, un deber de justicia y de Estado e, incluso, por qué no decirlo también, religioso. Era un deber de justicia, en primer lugar, porque todos los hombres, siendo iguales en humanidad, deberían tener el mismo derecho a la educación'. Era un deber de Estado, también, porque éste era la única entidad capaz de garantizar el acceso de todos los ciudadanos a la educación. Y era, por último, un deber religioso, porque de la misma forma que es un deber cristiano dar pan a los que tienen hambre así también lo es el de enseñar a los que no saben leer ni escribir ${ }^{\text {10 }}$. Pues bien, es precisamente dentro

4 Cf., Unamuno, Miguel: «Educación y herencia económica», en o. C., Madrid, Escelicer, I97I, vol. 9, p. 57I.

5 Cf., Unamuno, Miguel: Discurso pronunciado en el acto de apertura del curso 1903 a 1904 e inauguración del nuevo local de la escuela superior de industrias, de Bejar, en o. c., Madrid, Escelicer, 1971, vol. 9, pp. I32-133.

6 Cf., Unamuno, Miguel: Discurso pronunciado en el acto de la entrega de premios del concurso pedagógico celebrado en Orense en junio de 1903, en O. C., Madrid, Escelicer, I971, vol. 9, p. 82.

Unamuno, Miguel: Discurso pronunciado en el acto de la entrega de premios del concurso pedagógico celebrado en Orense en junio de 1903, en O. C., Madrid, Escelicer, I971, vol. 9, p. 82.

\& Cf., Unamuno, Miguel: Conferencia en el Teatro Cervantes de Málaga, el día 21 de agosto de I906, en O. C., Madrid, Escelicer, 1971, vol. 9, p. 187.

9 Cf., Unamuno, Miguel: Discurso pronunciado en el acto de la entrega de premios del concurso pedagógico celebrado en Orense en junio de 1903, en O. C., Madrid, Escelicer, 1971, vol. 9, p. 82.

ro Cf., Unamuno, Miguel: Discurso pronunciado en el acto de la entrega de premios del concurso pedagógico celebrado en Orense en junio de 1903, en O. C., Madrid, Escelicer, I97I, vol. 9, p. 84. 
UNAMUNO: LAS FUNCIONES EDUCATIVAS DEL ESTADO. DEL ESTADO DOCENTE

AL ESTADO ORGANIZADOR DE LA ENSEÑANZA EMANUEL JOSÉ MAROCO DOS SANTOS

de este posicionamiento teórico que se hace comprensible la crítica que Unamuno dirigió a Martínez Campos, en su ensayo «Pedagogía castrense», de I922, puesto que, para el bilbaíno, la campaña pedagógico-militar de España, en Marruecos, era un gravísimo error, en la medida en que no tenía sentido intentar educar a los moros cuando España adolecía de elevadas tasas de analfabetismo" ${ }^{\text {II }}$

En relación directa con el tema de la democratización de la enseñanza se ubica el problema de la enseñanza de la mujer. La posición de Unamuno es clara e intachable y se consustancia en la afirmación de que la mujer debería tener el mismo derecho que el hombre a la educación. Si hay algún texto donde Unamuno se acercó a dicho tema ése es sin duda el de la conferencia que pronunció en el Teatro Cervantes de Málaga, el día 2I de agosto de 1906. En dicha ocasión, se propuso analizar el problema de la educación de la mujer a partir del origen histórico del maestro $^{12}$. Para Unamuno, gran conocedor de la historia de la cultura occidental, la educación de la mujer se ha abandonado a lo largo de los siglos porque la finalidad de la educación consistió fundamentalmente en hacer buenos soldados. Por ello, dado que la mujer nunca habría de ser guerrera, nunca se la educó ${ }^{13}$. Y la Iglesia acabó más tarde por reiterar dicho problema cuando vinculó el telos de su misión docente con el sacerdocio ${ }^{\mathrm{T}}$. Lo cual quiere decir que nunca se educó a la mujer porque la finalidad del Estado y de la Iglesia, los únicos patronos de la educación, fue la de formar soldados y sacerdotes, respectivamente. Pues bien, dado que, para Unamuno, la mujer tenía un papel que desempeñar en la sociedad y que debería ser educada para realizarlo, cabría determinar qué tipo de educación pensó Unamuno para la mujer. Si se tiene en consideración la susodicha conferencia de 1906, percibimos que la educación que el bilbaíno propuso para la mujer no tenía nada que ver con la enseñanza de los bordados o de tareas típicamente femeninas, designadas como labores de su sexo ${ }^{15}$. Sin embargo, Unamuno nunca llegó a concretar su propuesta educativa, ni en la referida conferencia ni en sus escritos posteriores. Por ello, lo único que podremos decir a este propósito -pese al hecho de que, en muchos momentos de su obra, vinculase el papel de la mujer con su orientación biológica- ${ }^{16}$ es que Unamuno fue un claro defensor de la educación de la mujer, y que la concibió muy probablemente en la misma línea de la del hombre, no obstante los papeles diferenciados que ambos deben realizar en la sociedad según su pensamiento antropológico. Y esto es muy significativo,

"Cf., Unamuno, Miguel: «Pedagogía castrense», en El Mercantil Valenciano, Valencia, 04.VII.I922.

${ }_{12} C f$., Unamuno, Miguel: Conferencia en el Teatro Cervantes de Málaga, el día 2 I de agosto de 1906, en O. C., Madrid, Escelicer, I97I, vol. 9, p. I84.

13 Cf., Unamuno, Miguel: Conferencia en el Teatro Cervantes de Málaga, el día 2 I de agosto de 1906, en O. C., Madrid, Escelicer, I97I, vol. 9, p. I84.

${ }_{14}$ Cf., Unamuno, Miguel: Conferencia en el Teatro Cervantes de Málaga, el día 21 de agosto de 1906, en O. C., Madrid, Escelicer, 1971, vol. 9, p. I84.

is Cf., Unamuno, Miguel: Conferencia en la Sociedad de Ciencias, de Málaga, el 23 de agosto de I906, en O. C., Madrid, Escelicer, 1971, vol. 9, p. 209.

${ }^{16} C f$., Unamuno, Miguel: «La educación. Prólogo a la obra de Bunge, de mismo título», en o. C., Madrid, Escelicer, I966, vol. I, pp. IO20-IO2I. 
si se encuadra en su época histórica tan tumultuosa en lo que concierne a la afirmación de los derechos de las mujeres.

La enseñanza del bordado, por otra parte, es un símbolo de esclavitud de la mujer, esclavizada a eso que con una frase degradante llamamos «labores de su sexo». Se busca, distrayéndoles con esas futesas, mantenerles en cierta perpetua minoridad intelectual. Es ello una vergüenza y una forma de aquello de que a la mujer le basta con saber guisar y remendar los calzones del marido. // En el fondo, parece se trata de impedir el desarrollo de la dignidad humana, de todo lo más elevado y más noble ${ }^{17}$.

¿Cuáles fueron los motivos que Unamuno invocó para la democratización de la enseñanza? El primero y el principal ya lo hemos mencionado, es el que se refiere al hecho de que la educación es un derecho universal. Si todos los hombres son iguales entre sí, en lo que concierne a su naturaleza y dignidad, entonces la educación no puede ser un privilegio de algunos, sino de todos. Aquí, el hecho de que el hombre tenga una doble naturaleza, la biológica y la cultural, y de que esta última sólo se realice plenamente a través de la enseñanza, pone de relieve, según Unamuno, la importancia de la educación como un derecho universal. Empero, si se analiza su ensayo «La pirámide nacional», de I898, percibimos que la democratización de la enseñanza tiene por lo menos una virtud más: la del progreso intelectual de la sociedad. Para Unamuno, que, en este aspecto, vislumbra un claro paralelo entre la economía y la educación, del mismo modo que el progreso económico depende de la producción de artículos de universal consumo, en la medida en que "por el consumo medio del obrero se gradúa de la riqueza social» ${ }^{18}$, así también el progreso intelectual de un pueblo está subordinado al aumento de la instrucción primaria, ya que sólo la cultura general permite determinar el valor social del conocimiento especializado.

(I) Uno de los más claros signos del progreso intelectual de una sociedad, de su mayor cultura, es que aumente en ella la instrucción primaria en mayor medida que la facultativa ${ }^{19}$.

(2) La cultura general, los conocimientos sólidos al alcance a ser posible de todo el mundo, determinan el valor social de todo conocimiento especializado, como el salario real el precio de las $\operatorname{cosas}^{20}$.

Fue a partir de este último aspecto que Unamuno sostuvo, en el referido ensayo de I898, de forma obviamente polémica, que el mejor camino para el progreso intelectual de la sociedad española residiría en la suspensión de la segunda y tercera enseñanza, es decir, de la enseñanza media y universitaria, con vistas a convertir a sus profesores en maestros de primeras letras y a erradicar de este modo

${ }_{17}$ Unamuno, Miguel: Conferencia en la Sociedad de Ciencias, de Málaga, el 23 de agosto de I906, en O. C., Madrid, Escelicer, 1971, vol. 9, pp. 209-210.

${ }_{18}$ Cf., Unamuno, Miguel: «La pirámide nacional», en o. C., Madrid, Escelicer, 1968, vol. 3, p. 689.

19 Unamuno, Miguel: «La pirámide nacional», en O. C., Madrid, Escelicer, 1968, vol. 3, p. 689.

20 Unamuno, Miguel: «La pirámide nacional», en o. C., Madrid, Escelicer, 1968, vol. 3, pp. 689-69o. 
UNAMUNO: LAS FUNCIONES EDUCATIVAS DEL ESTADO. DEL ESTADO DOCENTE

AL ESTADO ORGANIZADOR DE LA ENSEÑANZA EMANUEL JOSÉ MAROCO DOS SANTOS

el analfabetismo. Siendo cierto que la concreción de dicha propuesta significaría un auténtico desastre cultural y científico, ya que la suspensión de la enseñanza media y universitaria supondría la destrucción del nivel intelectual del país, no es menos cierto también que tiene por lo menos el mérito de alertar sobre los efectos benéficos que la erradicación del analfabetismo tendría en el desarrollo intelectual, político y económico del país. Para Unamuno, el hecho de que la base de la pirámide nacional tuviese tan sólo un tercio de personas letradas hacía que los mejores talentos españoles no pudiesen desarrollar plenamente su actividad intelectual, científica y cultural por falta de ambiente propicio para ello, ya que era imposible sostener una elevada cumbre social a partir de una pequeña base de sustentación ${ }^{21}$. No nos extraña, pues, que se opusiese a lo que denominó especialismos: en primer lugar, porque sin una base fuerte de apoyo no contribuían en nada al desarrollo intelectual del país ${ }^{22}$ y, después, porque era difícil la distinción científica en el seno de una pirámide social muy escarpada ${ }^{23}$. He aquí, pues, la razón que llevó a Unamuno a proponer la democratización de la enseñanza como motor de la regeneración del país, aunque eso supusiese la liquidación del segundo y tercer grados de enseñanza.

La principal razón del marasmo en que yace nuestra juventud intelectual consiste en que hay muchos españoles que no saben leer siquiera, y de los que leen los más no "pronuncian». Debían suprimirnos a los catedráticos de segunda y tercera enseñanza, convirtiéndonos en maestros de instrucción primaria. Más de uno tendría que aprender de nuevo las cuatro reglas ${ }^{24}$.

En definitiva, Unamuno fue un gran defensor de la democratización de la enseñanza, es decir, de la enseñanza para todos independientemente del estrato social o del sexo de cada uno de los individuos, ya que, a su juicio, tanto hombres y mujeres como pobres y ricos tenían el mismísimo derecho de acceso al conocimiento humano. Por ello, creyó necesario erradicar el analfabetismo que lastraba a dos tercios de la población finisecular española aunque para ello fuese necesario suspender temporalmente la educación universitaria o facultativa. En esta toma de posición jugó un papel decisivo la importancia que la educación tiene en la formación del hombre, ya que Unamuno, al partir del hecho de que su naturaleza espiritual sólo se concreta plenamente a través de la educación, creyó que su defensa como derecho universal era simultáneamente la defensa del desarrollo de la naturaleza humana. Asimismo, en Unamuno, la defensa del derecho a la educación para todos no se reduce ni se limita a la defensa del progreso intelectual del país o a la defensa de igualdad de oportunidades, sino que se refiere más bien a la propia defensa del hombre, cuya naturaleza espiritual depende, simultáneamente, de los procesos de socialización y de educación.

${ }_{21}$ Cf., Unamuno, Miguel: «La pirámide nacional», en O. C., Madrid, Escelicer, 1968, vol. 3, p. 690. 22 Cf., Unamuno, Miguel: «La pirámide nacional», en O. C., Madrid, Escelicer, 1968, vol. 3, p. 690.

23 Cf., Unamuno, Miguel: «La pirámide nacional», en o. C., Madrid, Escelicer, 1968, vol. 3, p. 69I.

24 Unamuno, Miguel: «La pirámide nacional», en O. C., Madrid, Escelicer, 1968, vol. 3, p. 69I. 


\section{El Estado Docente: sólo al Estado compete educar}

He sido y soy decidido partidario del Estado docente ${ }^{25}$.

Si hay alguna propuesta educativa de Unamuno que mereció de parte de sus comentaristas una atención privilegiada ésa es sin duda la del Estado docente, tal como fue concebido e interpretado por el autor en la célebre conferencia Lo que ha de ser un rector en España, de I9I4. Unamuno, recupera aquí, pues, uno de los tópicos de los autores regeneracionistas, como Azaña, que empezó a defender dicha idea a partir de i9I. Con ello, no afirmamos que dicha idea, la del estatismo docente, no latiese en sus escritos anteriores, puesto que creemos que su génesis podría hallarse ya en su primer libro sobre el tema educativo, De la enseñanza superior en España, de i898, cuando Unamuno afirmó que era un mito la libre concurrencia aplicada a la educación $^{26}$, lo que afirmamos, sí, es que dicho concepto sólo aparece por primera vez en la mencionada conferencia de I9I4 y que, por ello, la legitimación del mismo deberá ser enfocada bajo un doble enfoque: en primer lugar, a partir de lo que Unamuno refiere en la mencionada conferencia y, después, a partir de las ideas que el autor fue defendiendo sobre la escuela pública y privada a lo largo de su quehacer intelectual hasta I9I4, ya que creemos que de este modo se hace más inteligible su alejamiento posterior con respecto a dicha idea. Empero, más allá y más acá de este cambio teórico, hay una verdad insoslayable a la cual no queremos rehuir y es la que define al «Unamuno educador» como un gran «defensor de la razón del Estado» ${ }^{27}$. Por ello, concordamos con Barros Dias y Herrero Castro cuando afirman que Unamuno, gran defensor del liberalismo y de la «no intromisión del Estado en la vida particular de los ciudadanos $»^{28}$, se destaca paradójicamente por la defensa del estatismo docente, esto es, por sostener, en términos educativos, una concepción autoritaria del Estado ${ }^{29}$, pero añadimos también que dicha actitud paradójica, lejos de ser específica del autor, refleja la clásica contradicción liberal que Unamuno asume como suya al aceptar el liberalismo como eje de su pensamiento filosófico. A este propósito quisiéramos subrayar que Unamuno tiene presente en su adhesión al liberalismo las ideas defendidas por autores como Gumersindo Azcaráte, Concepción Arenal, Gabriel Rodríguez y José Manuel Piernas Hurtado, que se insertan en la corriente intervencionista, que retomó también el propio Azaña.

25 Unamuno, Miguel: Lo que ha de ser un rector en España. Conferencia leída en el ateneo de Madrid, el 25 de noviembre de I9I4, en O. C., Madrid, Escelicer, I971, vol. 9, p. 310.

${ }_{26}$ Cf., Unamuno, Miguel: De la enseñanza superior en España, en O. C., Madrid, Escelicer, 1966, vol. i, p. 755 .

${ }_{27} C f$., Morón Arroyo, Ciriaco: Hacia el sistema de Unamuno: estudios sobre su pensamiento y creación literaria, Col. Referencias, $\mathrm{n}^{\circ}$. 2, Palencia, Cálamo, 2003, p. I9I.

${ }_{28}$ Cf., Barros Días, José Manuel: Miguel de Unamuno e Teixeira de Pascoaes: compromissos plenos para a educação dos povos peninsulares, Lisboa, Imprensa Nacional Casa da Moeda, vol. 2, 2002, p. 35.

${ }_{29}$ Cf., Herrero Castro, Santos: «Pensamiento socio-educativo de Miguel de Unamuno: estructura y cambio social en la España del primer tercio del siglo XX», Studia Paedagogica, Salamanca, n. ${ }^{\circ} 22$ (199I), p. 55 . 
UNAMUNO: LAS FUNCIONES EDUCATIVAS DEL ESTADO. DEL ESTADO DOCENTE

AL ESTADO ORGANIZADOR DE LA ENSEÑNAZA

EMANUEL JOSÉ MAROCO DOS SANTOS

Si se analiza con algún detalle la susodicha conferencia de igi4 verificamos que la única razón que Unamuno invocó -la única, hay que subrayarlo- para la legitimación del Estado docente es la que se refiere a la calidad de la enseñanza, ya que, a su juicio, la privada era cien veces peor que la pública, que -afirmémoslocalificaba de muy mala ${ }^{30}$. Y en este aspecto concuerdan todos sus comentaristas, de entre los cuales destacamos a Herrero Castro ${ }^{31}$ y Blanco Prieto ${ }^{32}$, puesto que sostienen que la posición de Unamuno a favor del Estado docente se debe a su honda convicción de que si el Estado abandonara la docencia ésta acabaría por perder sus flacos niveles de calidad. Y a este propósito es curioso observar también que, en la igualmente célebre conferencia que Unamuno pronunció en la Real Academia de Jurisprudencia y Legislación, de Madrid, el 3 de enero de 1917, titulada Autonomía Docente, nuestro autor volvió a justificar su posición a favor del Estado docente, invocando la mismísima razón: la de la infinita superioridad de la enseñanza pública. Y es curioso observarlo -decíamos- porque este hecho tendrá implicaciones decisivas en su alejamiento posterior con respecto a su concepción del Estado docente. Si se plantea el problema del estatismo docente tan sólo en términos cualitativos, la enseñanza privada no podrá nunca ser rechazada si cumple con dicho requisito. Cabría subrayar, tan sólo, por el momento, que Unamuno ya había enunciado dicha crítica en ocasiones anteriores como podemos verificar en la conferencia que pronunció en el Teatro Cervantes de Málaga, el 2i de agosto de 1906, donde afirma que siendo muy mala la enseñanza que el Estado imparte, es aun así la única que merece dicho nombre ${ }^{33}$.

Claro está que aquí hay un mal, yo creo que un mal necesario; es eso de que tantas veces se suele hablar, en contra, sobre todo por elementos de extrema derecha, y es el Estado docente.

Se combate mucho al Estado docente; creo que es un mal que sea el Estado el que tenga que enseñar, pero, como digo, es un mal necesario. La ciencia oficial podrá ser menguada, pero hoy, mala y todo, es la única que hay y la única que merece el nombre de enseñanza. La que dan los particulares, la privada, la de las Asociaciones, es infinitamente peor; hacen que enseñan, y no enseñan nada. Claro que la oficial tiene el inconveniente de una cierta irresponsabilidad, de una falta de inspección técnica, cuando lo capital, lo importante en la enseñanza, no es el material, es el personal ${ }^{34}$.

$3^{\circ} C f$., Unamuno, Miguel: Lo que ha de ser un rector en España. Conferencia leída en el ateneo de Madrid, el 25 de noviembre de I9I4, en O. C., Madrid, Escelicer, I97I, vol. 9, p. 31 IO.

${ }^{31} \quad C f$., Herrero Castro, Santos: «Pensamiento socio-educativo de Miguel de Unamuno: estructura y cambio social en la España del primer tercio del siglo xx», Studia Paedagogica, Salamanca, n. ${ }^{\circ} 22$ (I99I), p. 59.

${ }_{32} C f$., Blanco Prieto, Francisco: Unamuno, profesor y rector en la Universidad de Salamanca, Salamanca, Hergar Ediciones Antema, 20II, p. 6ro.

33 Cf., Unamuno, Miguel: Conferencia en el Teatro Cervantes de Málaga, el día 2 de agosto de I906, en O. C., Madrid, Escelicer, 1971, vol. 9, p. I84.

${ }_{34}$ Unamuno, Miguel: Autonomía Docente. Conferencia pronunciada en la sesión pública de 3 de enero de I9I7, en la Real Academia de Jurisprudencia y Legislación, de Madrid, en O. C., Madrid, Escelicer, 1971, vol. 9, p. 344. 
Sin embargo, los argumentos que Unamuno defendió desde i 898 a favor de la escuela pública, y que podrían legitimar su concepción de Estado docente, no se circunscribieron a la rotunda afirmación de que ésta era mejor que la privada. De hecho, basta no pasar por alto el discurso que Unamuno pronunció en el Palacio de la Biblioteca y Museos Nacionales de Madrid, ante el rey don Alfonso XIII, en representación de la Universidad de Salamanca, el día 24 de mayo de I902, para percibir que el principal argumento que el bilbaíno sostuvo a favor de la escuela pública -y, por lo tanto, del Estado docente- radicaba en la afirmación de que sólo ésta podría impedir que la enseñanza se subordinase al lucro y a fines ajenos a la cultura y al progreso humano. Con dicha toma de posición, aunque no lo haya declarado explícitamente, Unamuno creyó que sólo un Estado docente podría sostener una enseñanza libre y desinteresada ${ }^{35}$. Fue por ello que Unamuno pidió dos años más tarde a S. M. el Rey, en el discurso que pronunció en el Paraninfo de la Universidad de Salamanca, el i de octubre de 1904, que su universidad nunca dejase de estar bajo el apoyo y amparo del propio Estado ${ }^{36}$.

Pues bien, ante la aparente fuerza de dicho argumento, cabría preguntar por qué motivo Unamuno no lo expuso en las susodichas conferencias de 1914 y 1917, donde propuso, por primera vez, de forma explícita, su concepción de Estado docente. Si nuestros análisis no están desencaminados creemos que el motivo no puede ser otro que su progresiva percepción de que no hay Estados aconfesionales ni educaciones ideológicamente neutras. Y si esto es así, la enseñanza pública, independientemente del deseo o no de sus defensores, está también subordinada a una determinada ideología o «confesión». No nos extraña, pues, que con el paso del tiempo Unamuno acabase por abandonar la idea del Estado docente a favor de un Estado concebido como entidad organizadora de la enseñanza. Para el último Unamuno, como veremos más adelante, podría haber escuelas, institutos y universidades privados, con esta o aquella ideología, siempre y cuando estas instituciones se subordinasen a las exigencias y existencia del propio Estado. Cabría subrayar, tan sólo, por el momento, en la línea de Yvonne Turin ${ }^{37}$, que el abandono del estatismo docente por parte de Unamuno se debió a los problemas inherentes a la escuela única, ya que el paso del monopolio educativo de la Iglesia al Estado hacía que surgiese un nuevo problema inherente a la confesión del Estado y al componente ideológico de la educación. De hecho, si el servicio de cultura y educación fuera de la única competencia y responsabilidad del propio Estado, los estudiantes estarían subyugados a una nueva idolatría que, por oposición a la de la Iglesia, sería laica. Fue precisamente por ello que Unamuno, en un primer momento, se opuso al artículo 48 de la Constitución de la República Española

35 Cf., Unamuno, Miguel: Discurso leído en el palacio de la biblioteca y museos nacionales, de Madrid, ante el rey don Alfonso XIII, en Representación de la Universidad de Salamanca, el día 24 de Mayo de I902, en O. C., Madrid, Escelicer, I971, vol. 9, p. 79.

${ }_{36}$ Cf., Unamuno, Miguel: Discurso pronunciado en el Paraninfo de la Universidad de Salamanca, ante el Rey Don Alfonso XIII, que presidió la inauguración del curso académico, el día I de octubre de 1904, en O. C., Madrid, Escelicer, 1971, vol. 9, p. 137.

${ }_{37}$ Cf., Turin, Yvonne: Miguel de Unamuno Universitaire, Paris, sevpen, 1982, pp. I02-I03. 
UNAMUNO: LAS FUNCIONES EDUCATIVAS DEL ESTADO. DEL ESTADO DOCENTE

AL ESTADO ORGANIZADOR DE LA ENSEÑANZA EMANUEL JOSÉ MAROCO DOS SANTOS

de I93I, ya que creía que el laicismo educativo, en cuanto absoluta negación del sentimiento religioso, se oponía a la idiosincrasia del pueblo español. Empero, dado que percibió que, en términos ideológicos, no puede haber Estados ni educaciones neutrales, renunció, en un segundo momento, a su propuesta inicial del Estado docente, ya que éste en vez de salvaguardar las libertades culturales, como lo creía cuando lo propuso, terminaba por negarlas. De este modo, podríamos afirmar que fue su arraigado liberalismo intelectual y religioso lo que lo llevó a rechazar su propuesta inicial del Estado docente.

Pero hay otro aspecto fundamental que llevó a Unamuno a considerar la importancia del Estado docente y es el que se refiere a la génesis y origen de la enseñanza pública. Para Unamuno, si se tiene en consideración la conferencia que pronunció en el Teatro Cervantes de Málaga, el 2i de agosto de 1906, el interés de los pueblos por la educación no fue típicamente religioso sino del Estado. Fueron los Estados los que, a partir, primero, del movimiento de la Reforma y, después, de los de la Ilustración y del Enciclopedismo, se interesaron por la educación de los pueblos y han implementado la enseñanza primaria obligatoria ${ }^{38}$. Sólo después las órdenes religiosas se han dedicado a la enseñanza. Pues bien, Unamuno, inmediatamente después de exponer dicha tesis, que, en términos fácticos, no nos merece ninguna objeción, introduce un dato nuevo que, como lo expone, denigra la enseñanza privada: las órdenes religiosas sólo preparan a sus alumnos convenientemente porque el Estado así lo exige, pues si no lo exigiese no lo harían. Y al partir de esta crítica, legitima su concepción del Estado docente en cuanto motor de la regeneración del país ${ }^{39}$. Para Unamuno, como sostiene Herrero Castro, y hablamos del Unamuno anterior a su regreso del destierro, sólo el Estado debería tener funciones docentes, ya que sólo él podría salvaguardar las libertades culturales de cada individuo ${ }^{40}$. Sin embargo, con su regreso a España, y con motivo de la redacción de la Constitución española de I93I, Unamuno tomó conciencia de que el Estado no podía salvaguardar las libertades culturales, como lo demuestra su crítica al célebre artículo $48 .^{\circ}$, en la medida en que no podía ser ideológicamente neutro. Por ello, se alejó de su idea inicial a favor de la defensa de la enseñanza privada. Si hay escuelas de todas las ideologías y colores, y si los alumnos y sus padres las elijen según sus convicciones religiosas, intelectuales o políticas, entonces las libertades culturales podrán ser salvaguardadas. En este aspecto, es curioso observar la dinámica del pensamiento del autor. En un primer momento, percibió que la Iglesia, ideológicamente confesional, se oponía a las libertades individuales, mayormente la suya de tonos heterodoxos y protestantes, y por ello defendió un Estado docente capaz de garantizar todas las libertades

${ }_{38}$ Cf., Unamuno, Miguel: Conferencia en el Teatro Cervantes de Málaga, el día 2 I de agosto de 1906, en O. C., Madrid, Escelicer, 1971, vol. 9, p. 185.

39 Cf., Unamuno, Miguel: Discurso leído en la solemne apertura del curso académico de rgoo a I9oI, en la Universidad de Salamanca, en O. C., Madrid, Escelicer, I97I, vol. 9, p. 60.

$4^{\circ}$ Cf., Herrero Castro, Santos: «Pensamiento socio-educativo de Miguel de Unamuno: estructura y cambio social en la España del primer tercio del siglo XX», Studia Paedagogica, Salamanca, n. ${ }^{\circ} 22$ (1991), p. 59. 
a partir -afirmémoslo- de la idiosincrasia cultural del pueblo español. Y en un segundo momento, al tomar conciencia de que el Estado no podía ser neutral, y ante el riesgo de que éste se hiciese laico abandonó su concepción autoritaria del Estado y de la educación a favor de la libertad de enseñanza, pues sólo así creía que podrían salvaguardarse las libertades individuales. Lo que cabe preguntar, pues, es si Unamuno rechazaría su concepción del Estado docente si la Constitución española de 193 I se declarase simultánea y contradictoriamente a favor de la libertad religiosa y la religión popular española. La respuesta sólo puede ser, como es obvio, negativa, porque la neutralidad ideológica, en el Unamuno defensor del Estado docente, está referida al Volksgeist español.

Los ensayos «La universidad hace veinte años» $\mathrm{y}$ «Enseñanza religiosa laica», ambos de 1933, son, a nuestro juicio, la expresión máxima de dicho cambio teórico, ya que, en los mismos, y en contra de lo que había defendido hasta el momento, Unamuno unió su voz a la del clero español considerando injusto el artículo $26^{\circ}{ }^{\circ 1}$ de la Constitución española de I93I, en el cual se prohibía el ejercicio de la función docente de la Iglesia. Pese al hecho de que Unamuno no dijese nada acerca de si las instituciones educativas privadas religiosas podrían o no conferir grados y examinar, lo cierto es que legitimó su existencia siempre y cuando sus docentes tuviesen los títulos académicos que el Estado exige y se sometiesen a su inspección y vigilancia. Con esta toma de posición, Unamuno terminó por proponer una nueva función para el Estado que deja de ser tan sólo la de educar para pasar a ser también la de organizar, inspeccionar y vigilar todas las instituciones de enseñanza. Unamuno transita, pues, de una concepción de Estado docente hacia una concepción de Estado organizador de la enseñanza.

La campaña jesuítica en pro de la enseñanza libre ha sido la causa principal del suicidio en España de la Compañía de Jesús. El que esto escribe, que tuvo experiencia larga de cómo enseñaban y de cómo no enseñaban los de Deusto, que tiene formado concepto de la pedagogía jesuítica, no ha de exponerlo ahora aquí. Eso sí, ha de repetir, pues, lo ha dicho más de una vez, que estima injusta la disolución de la Compañía e injusta la prohibición de enseñar a las Órdenes religiosas si sus miembros poseen los títulos que el Estado exige y se someten a la inspección y vigilancia de éste. Y ahora sólo me compete afirmar que la enseñanza universitaria, con todos sus defectos, era en aquellos tiempos muy superior a la de esas otras instituciones libres ${ }^{42}$.

Si hasta aquí hemos analizado el Estado docente en su función pedagógica (educación del niño), ahora, quisiéramos analizarlo, aunque de forma sinóptica, en su misión demagógica (educación del pueblo) ${ }^{43}$, ya que este vínculo fue intencionadamente propuesto por el propio Unamuno en la ya mencionada conferencia de 19I4. El por aquel entonces destituido rector de la Universidad de

${ }^{41}$ Cf., Constitución de la República Española de 1931, art. 26.

${ }_{42}$ Unamuno, Miguel: «La universidad hace veinte años», en O. C., Madrid, Escelicer, 1970, vol. 8, p. 1197 .

${ }^{43}$ Cf., Unamuno, Miguel: Lo que ha de ser un rector en España. Conferencia leída en el ateneo de Madrid, el 25 de noviembre de I9I4, en O. C., Madrid, Escelicer, 1971, vol. 9, p. 313. 
UNAMUNO: LAS FUNCIONES EDUCATIVAS DEL ESTADO. DEL ESTADO DOCENTE

AL ESTADO ORGANIZADOR DE LA ENSEÑANZA

EMANUEL JOSÉ MAROCO DOS SANTOS

Salamanca empieza dicho tema afirmando que su misión como rector no fue más que la de preparar una universidad digna de un Estado docente ${ }^{44}$, es decir, de una universidad capaz de formar intelectual y espiritualmente el propio Estado ${ }^{45}$. Para Unamuno, si había algún problema que consumía a su España finisecular éste era sin duda el de la inmoralidad de sus políticos, que, por «no tener un concepto normativo y claro de lo que ha de ser un Estado» ${ }^{46}$, organizaban su actividad política en torno a su reelección o reposición ${ }^{47}$, lo cual impedía la existencia del propio Estado ${ }^{48}$. He aquí, pues, la razón por la cual Unamuno creyó que un Estado docente debería también privilegiar la educación del pueblo, siguiendo la misma línea ideológica de los regeneracionistas. Se trataba, en último análisis, de dar al pueblo conciencia de sí mismo y de implicarlo en los problemas del país. Fue por ello que Unamuno emprendió con sus compañeros del claustro la famosa campaña agraria ${ }^{49}$. Aquí, no mencionamos las demás facetas del Unamuno demagogo o educador del pueblo, que se correlacionan con el Unamuno novelista, dramaturgo, poeta, ensayista y conferenciante, en la medida en que no sólo no se refirió a las mismas en la mencionada conferencia, sino también porque ya las hemos analizado en otro lugar. Para nosotros, lo fundamental, por ahora, es señalar tan sólo que, a juicio de Unamuno, el Estado docente se concreta también a través de la educación del pueblo, es decir, a través de la formación de una democracia de ideas o de una conciencia pública capaz de reflexionar sobre los problemas políticos, sociales, económicos, educativos y religiosos de su época histórica.

Siempre me preocupó la falta de Estado. Y no hay Estado porque no hay democracia. Sin democracia, no cabe Estado digno de ese nombre. Y no hay democracia donde no hay conciencia pública, ni hay conciencia pública donde no hay ideas. ¿Cómo, si no, a través de ideas, de ideas generales, racionales, no de expedientes políticos, puede un pueblo conocer y sentir sus males? Al que no piensa, ni le duele. Sólo nos duele España, nos duele de veras, a los que pensamos. Y el pueblo no se revuelve contra sus males porque no le duelen, y no le duelen porque no le hemos enseñado a pensar en ellos ${ }^{50}$.

En definitiva, el Estado docente fue, paradójicamente al espíritu liberal de su autor, la gran propuesta educativa del rector salmantino. Para el Unamuno

44 Cf., Unamuno, Miguel: Lo que ha de ser un rector en España. Conferencia leída en el ateneo de Madrid, el 25 de noviembre de I9I4, en O. C., Madrid, Escelicer, 1971, vol. 9, p. 313.

${ }^{4} \quad C f$., Unamuno, Miguel: Lo que ha de ser un rector en España. Conferencia leída en el ateneo de Madrid, el 25 de noviembre de I9I4, en O. C., Madrid, Escelicer, 1971, vol. 9, p. 313.

${ }^{46} C f$., Unamuno, Miguel: Lo que ha de ser un rector en España. Conferencia leída en el ateneo de Madrid, el 25 de noviembre de I9I4, en O. C., Madrid, Escelicer, 1971, vol. 9, p. 313.

${ }_{47} C f$., Unamuno, Miguel: Lo que ha de ser un rector en España. Conferencia leída en el ateneo de Madrid, el 25 de noviembre de I9I4, en O. C., Madrid, Escelicer, I97I, vol. 9, p. 3 I4.

${ }_{48} C f$., Unamuno, Miguel: Lo que ha de ser un rector en España. Conferencia leída en el ateneo de Madrid, el 25 de noviembre de I9I4, en O. C., Madrid, Escelicer, I971, vol. 9, p. 310.

49 Cf., Unamuno, Miguel: Lo que ha de ser un rector en España. Conferencia leída en el ateneo de Madrid, el 25 de noviembre de I9I4, en O. C., Madrid, Escelicer, 1971, vol. 9, pp. 310-3II.

so Unamuno, Miguel: Lo que ha de ser un rector en España. Conferencia leída en el ateneo de Madrid, el 25 de noviembre de I9I4, en O. C., Madrid, Escelicer, 1971, vol. 9, p. 314. 
anterior a 1931, esto es, para el Unamuno defensor del Estado docente, sólo el Estado debería tener funciones educativas, porque sólo él podría organizar una enseñanza libre y desinteresada, esto es, una enseñanza no subordinada al lucro $\mathrm{o}$ a intereses ajenos a la cultura y al progreso humano. $\mathrm{Y}$ a este factor sumamente decisivo, el de la neutralidad ideológica, se juntaban dos buenos argumentos más a favor de la escuela pública: el primero, el que se refiere al hecho de que, a juicio de Unamuno, ésta fuese cualitativamente mejor que la privada; y, después, el hecho de que las instituciones particulares de enseñanza sólo enseñasen lo que el Estado así lo exigía. Sin embargo, con su regreso a España, y con motivo de la redacción de la Constitución española de I93I, Unamuno se dio cuenta de que no hay Estados aconfesionales ni enseñanzas ideológicamente neutras. Por ello, unió su voz a del clero español en contra de la escuela única y en contra de la prohibición de enseñar de las órdenes religiosas. De este modo, Unamuno transitó de una concepción de Estado docente a una concepción de Estado organizador de la enseñanza. Y transita -decíamos-, porque la asunción de una determinada ideología o confesión por parte del Estado no consustancial al Volksgeist nacional tendría consecuencias desastrosas para el país si toda la educación dependiese del propio Estado.

\section{El Estado Organizador de la Enseñanza: la inspección de los docentes y otras funciones}

«No es posible organizar el Estado sino por medio de la educación; no es posible organizar la educación sino por medio del Estado». Sentencia es ésta del autor, con la que estoy de completo acuerdos.

Unamuno, en su prólogo a la edición española de obra de Bunge La educación, adopta como suya una expresión fundada en dos enunciados o proposiciones que, en términos organizativos, considera el Estado y la educación como dos realidades esencialmente interdependientes. Para Unamuno, que en esto sigue a Bunge, el Estado sólo se organiza por medio de la educación, como la educación por medio del Estado. Lo mismo es decir que la educación es la condición de posibilidad del propio Estado como el Estado de la educación. Dejando a un lado el primer axioma, el que afirma que el Estado sólo se organiza por medio de la educación, para que nos centremos, por ahora, en el segundo, es obvio que, para Unamuno, sólo el Estado puede organizar la educación. No nos extraña, pues, que Unamuno se rebelase en contra de los artículos $295 .^{\circ}$ y $296 .^{\circ}$ de la Ley de Instrucción Pública de 9 de septiembre de I857 así como del artículo $2 .^{\circ}$ del Concordato de I85I, ya que, para Unamuno, la inspección de los profesores y de los libros de texto debería ser de la competencia exclusiva del propio Estado y no de la Iglesia.

¿I Unamuno, Miguel, «La educación. Prólogo a la obra de Bunge, de mismo título», en o. C., Madrid, Escelicer, 1966, vol. I, p. I02I. 
UNAMUNO: LAS FUNCIONES EDUCATIVAS DEL ESTADO. DEL ESTADO DOCENTE

AL ESTADO ORGANIZADOR DE LA ENSEÑNAZA

EMANUEL JOSÉ MAROCO DOS SANTOS

Si hay alguna línea de interpretación del texto unamuniano, en lo que respecta a las relaciones políticas que median entre las realidades del Estado y de la Iglesia, ésa es sin duda la que hace hincapié en el concepto de Estado laico, y en la correlativa división de los poderes temporal y espiritual. En este aspecto, son bastante demostrativos los varios y sucesivos enfrentamientos que Unamuno mantuvo con la Iglesia católica, dentro de los cuales podríamos destacar, fuera del ámbito educativo, la crítica que Unamuno dirigió a la intromisión de la Iglesia católica en las guerras coloniales de fin de siglo, que sostuvo España contra Cuba y Filipinas $^{s^{2}}$. Empero, es dentro del ámbito educativo donde late con mayor vigor su sui generis concepción de Estado laico, que se asienta en la mencionada división entre el Estado y la Iglesia, pero sin que ello signifique que el Estado se declare aconfesional. En lo que concierne al tema, cabría subrayar, tan sólo, por ahora, que dichos enfrentamientos han valido a Unamuno la censura post mortem de su Del sentimiento trágico de la vida, de 1913, y de su Agonía del cristianismo, de 1924, por la Congregación del Santo Oficio, el 23 de enero de $1957^{33}$.

Si se tiene en consideración la ponencia que Unamuno presentó en la II Asamblea Universitaria, celebrada en Barcelona en el año de 1905, La enseñanza universitaria, percibimos que el bilbaíno estaba manifiestamente en contra de los artículos $295 .^{{ }_{54}} \mathrm{y} 296{ }^{0_{55}}$ de la Ley de Instrucción Pública de 9 de septiembre de I857, así como del artículo $2 .^{\circ}$ del Concordato de $185 I^{56}$, puesto que, a su juicio, era verdaderamente inaceptable que los obispos y demás prelados tuviesen el poder de inspección en la enseñanza, ya sea para impedir la divulgación de doctrinas opuestas al catolicismo, ya sea para censurar libros heréticos ${ }^{57}$. En lo que concierne al tema, nos parece muy significativa la conferencia que el bilbaíno pronunció en la Real Academia de Jurisprudencia y Legislación, de Madrid, en el año de 1917, ya que, en la misma, volvió a criticar el poder de inspección de la Iglesia, pero, ahora, a la luz del artículo 170. ${ }^{098}$ de la mencionada Ley Moyano, en el cual se afirma que los profesores pueden ser inhabilitados de sus funciones siempre (I) «que no cumpl[an] con los deberes de su cargo, (2) que infund[an] en sus discípulos doctrinas perniciosas o (3) que [sean] indignos por su conducta de pertenecer al profesorado»s. Aquí, el hecho de que

s2 Cf., Raut, François: «"Mi defensa” o el borrador de una contestación inédita a la tentativa de destitución de Unamuno del rectorado de Salamanca por el obispo Cámara (finales de 1903 - principios de 1904)», Cuadernos de la Cátedra Miguel de Unamuno, Salamanca, vol. 39 (2004), p. 2I.

53 Cf., Madruga Méndez, Joaquín: Miguel de Unamuno: profesor y político, Salamanca, Gráficas Cervantes, 2007, pp. 67-68.

${ }_{54}$ Cf., Ley de Instrucción Pública de 9 de septiembre de 1857 , art. 295.

"Cf., Ley de Instrucción Pública de g de septiembre de 1857, art. 296.

56 Cf., Concordato de I85I, art. 2.

57 Cf., Unamuno, Miguel: La enseñanza universitaria. Ponencia presentada a la II Asamblea Universitaria, celebrada en Barcelona del 2 al 7 de enero de I905, en O. C., Madrid, Escelicer, I97I, vol. 9, p. I43.

${ }_{58}$ Cf., Ley de Instrucción Pública de 9 de septiembre de 1857 , art. I70.

59 Cf., Unamuno, Miguel: Autonomia Docente. Conferencia pronunciada en la sesión pública de 3 de enero de I9I7, en la Real Academia de Jurisprudencia y Legislación, de Madrid, en O. C., Madrid, Escelicer, 1971, vol. 9, p. 346. 
Unamuno interpretase el concepto de doctrinas perniciosas como difusión de ideas contrarias al credo católico ${ }^{60}$ nos permite comprender no sólo la importancia que el protestantismo liberal alemán tuvo en la formación de su pensamiento, sino también su exigencia de cientificidad dentro del mundo académico. Para Unamuno, era tan importante la afirmación de una religiosidad libre de cualquier tipo de dogmatismo doctrinal, que permitiese que el creyente examinase sus propias creencias, como un magisterio estructurado en torno al concepto de verdad científica, ya que los profesores sólo deberían ser inhabilitados de sus funciones cuando su maestría se estructurase en evidentes errores científicos ${ }^{61}$.

(I) C'est une grosse erreur de croire que l'Eglise catholique, religion officielle d'Etat, s'introduise dans notre enseignement public. La loi sur l'Instruction $\mathrm{Pu}-$ blique, encore en vigueur, de I857, et le Concordat entre l'Espagne et le SaintSiège, confèrent aux évêques le droit d'exercer cette inspection : mais, en fait, ils ne l'exercent jamais. Et mal leur en prendrait, s'ils l'essayaient !62.

(2) Es menester que la absoluta y perfecta libertad de la investigación y de la exposición científica en los centros de docencia oficial esté, no sólo protegida por la costumbre y la conciencia pública, sino, además, solemnemente garantizada por la ley $\mathrm{G}^{63}$.

Si hay alguna prueba de que Unamuno no aceptaba de ningún modo la intromisión de la Iglesia en el ámbito educativo español ésa es sin duda la que se relaciona con su reacción a la afirmación de que dichas leyes eran leyes en desuso, porque, para Unamuno, la vigencia o no de una ley no se medía por uso o desuso, o por las costumbres, sino por su aprobación o derogación parlamentarias ${ }^{64}$. Por lo demás, si se tiene en cuenta su célebre conferencia Lo que ha de ser un rector en España, de 19I4, percibimos que, para Unamuno, casos como el de la muerte de un profesor universitario al que no se le rindieron los honores fúnebres académicos no eclesiásticos por no haber muerto dentro de la Iglesia católica ${ }^{65}$ o como el de una maestra de escuela a la que pretendían remover de su cargo nada más que

6o Cf., Unamuno, Miguel: Autonomía Docente. Conferencia pronunciada en la sesión pública de 3 de enero de I9I7, en la Real Academia de Jurisprudencia y Legislación, de Madrid, en O. C., Madrid, Escelicer, 1971, vol. 9, p. 346.

${ }_{61} \quad C f$., Unamuno, Miguel: Autonomía Docente. Conferencia pronunciada en la sesión pública de 3 de enero de I9I7, en la Real Academia de Jurisprudencia y Legislación, de Madrid, en o. C., Madrid, Escelicer, 1971, vol. 9, p. 346.

${ }_{62}$ Unamuno, Miguel : «L'instruction publique en Espagne», en Études Diplomatiques, Paris, (mayo I9I4), p. 28.

${ }_{63}$ Unamuno, Miguel: La enseñanza universitaria. Ponencia presentada a la II Asamblea Universitaria, celebrada en Barcelona del 2 al 7 de enero de 1905, en O. C., Madrid, Escelicer, 1971, vol. 9, p. I43.

${ }^{64}$ Cf., Unamuno, Miguel: Autonomía Docente. Conferencia pronunciada en la sesión pública de 3 de enero de I9I7, en la Real Academia de Jurisprudencia y Legislación, de Madrid, en O. C., Madrid, Escelicer, 1971, vol. 9, p. 346.

${ }_{6} C f$., Unamuno, Miguel: Lo que ha de ser un rector en España. Conferencia leída en el ateneo de Madrid, el 25 de noviembre de I9I4, en O. C., Madrid, Escelicer, I971, vol. 9, pp. 307-308. 
UNAMUNO: LAS FUNCIONES EDUCATIVAS DEL ESTADO. DEL ESTADO DOCENTE AL ESTADO ORGANIZADOR DE LA ENSEÑNAZA EMANUEL JOSÉ MAROCO DOS SANTOS

por ser cristiana protestante ${ }^{66}$ eran, claramente, atentatorios contra la dignidad humana y que, por ello, deberían ser combatidos con la derogación de los susodichos artículos de la Ley Moyano, de I857, y del Concordato de I85I.

Muchas veces he dicho sobre ello y tendré aún que decir. Lo de laico es un término completamente indefinido, aunque parezca otra cosa. ¿No confesional?, se dirá. Pero el laicismo que aquí se predica es confesional. Ni puede ser de otro modo, pues a una confesión no se la combate sino con otra confesión. ¡Enseñanza neutral! ¿Neutral? Si uno tiene que confiar la crianza de un hijo a una nodriza, ¡trabajo le mando si va a buscar una con leche neutral, esterilizada, o pasteurizada! La leche de la nodriza -como la de la madre- lleva el dejo de los humores de ella. $\mathrm{Y}$ así, un maestro o maestra cualquiera, si es persona que tiene sus creencias y sus increencias, su confesión, su visión y su sentimiento del mundo. Ahora, ¡si ha de limitarse a administrar el biberón pedagógico y metodológico...! Que tampoco es neutral ${ }^{67}$.

Pues bien, dado que hasta ahora hemos analizado el Estado, en cuanto entidad organizadora de la enseñanza, en lo que se refiere a la inspección de los profesores y de los libros de texto, podría criticarse dicha interpretación afirmando que la propuesta de Unamuno de derogación de los mencionados artículos de la Ley Moyano y del Concordato de $1855^{68}$, es simultánea con su concepción de Estado docente, o sea, se nos podría criticar la legitimidad interpretativa, e incluso teórica, del presente apartado -que hemos intitulado intencionadamente «Estado organizador de la enseñanza»-, a partir de la afirmación de que Unamuno propuso la derogación de los mencionados artículos dentro del contexto del Estado docente. Y a esta crítica, de por sí bastante significativa, se podría añadir otra: en el texto unamuniano nunca surge el concepto de Estado Organizador de la Enseñanza. Sin embargo, si se tiene en consideración su pensamiento educativo posterior a su regreso del exilio, percibimos que Unamuno como reacción al artículo $488^{\text {.69 }}$ de la Constitución de la República Española de I93I, se alejó de su concepción de Estado docente al criticar la prohibición de enseñar impuesta a las órdenes religiosas $y$, por ende, la escuela única. Y este cambio es decisivo, ya que lo hizo transitar de su concepción de Estado docente a la del Estado en cuanto entidad organizadora de la enseñanza, pese al hecho de que Unamuno nunca lo haya mencionado explícitamente en sus textos. Y es dentro de este cambio teórico-conceptual, y sólo dentro de él, que tiene sentido la inspección de los profesores como una de las tareas propias de un Estado Organizador de la Enseñanza y, por ello, el presente apartado. Empero, allende de la inspección de los profesores y de los libros de texto ¿qué otras funciones debería tener el Estado? Si es cierto que, según lo que Unamuno nos dijo, no podemos responder sino de forma insuficiente, ya

${ }_{66}$ Cf., Unamuno, Miguel: Lo que ha de ser un rector en España. Conferencia leída en el ateneo de Madrid, el 25 de noviembre de 1914, en O. C., Madrid, Escelicer, 1971, vol. 9, p. 308.

${ }_{77}$ Unamuno, Miguel: «Schura Waldajewa», en O. C., Madrid, Escelicer, 1969, vol. 7, p. II48.

68 Cf., Concordato de I85I, art. 2.

69 Cf., Constitución de la República Española de 193I, artículo 48. 
que más allá de manifestarse en contra de la autonomía universitaria nada nos ha dicho sobre las funciones del Estado Organizador de la Enseñanza, no deja de ser igualmente cierto que por lo menos tuvo el mérito de subrayar el hecho de que sólo el Estado puede organizar la educación como lo prueba la crítica que dirigió a las instituciones privadas de enseñanza, que, a su juicio, sólo enseñaban lo necesario porque el Estado así lo exigía. No nos extrañaría, pues, si Unamuno pensase que sólo el Estado tenía competencia legal para determinar las asignaturas y los contenidos impartidos en los dos primeros grados de enseñanza.

Para finalizar este apartado quisiéramos detenernos, todavía, en el caso Ferrer, sobre todo en la toma de posición de Unamuno a favor del cierre de la Escuela Moderna. Con ello, no olvidamos el hecho de que Unamuno se haya autoeximido de haber defendido el fusilamiento de Ferrer y el cierre de sus escuelas, en su ensayo "Confesión de culpa», de $1917^{70}$. De este modo, más allá y más acá de los motivos que erradamente han conducido a Unamuno a rebelarse en contra de Ferrer Guardia, que se correlacionan (I) con el espíritu antirreligioso de la Escuela Moderna ${ }^{71}$, (2) con la campaña que Europa hizo contra España en lo que respecta a su fusilamiento ${ }^{72}$ e, incluso, (3) con el desconocimiento de todos los factores implicados en el proceso ${ }^{73}$, lo que nos importa, por ahora, es determinar los argumentos que Unamuno invocó para el cierre de su escuela, ya que los mismos demostraban uno de los fundamentos políticos clave de su pensamiento educativo. En lo que concierne al tema, la carta que Unamuno envió a Casimiro González Trilla, el I2 de noviembre de I909, no deja lugar a dudas cuanto al papel que la escuela debe tener en la organización del Estado ${ }^{74}$. Para Unamuno, el cierre de la Escuela Moderna era enteramente justo, porque, en la misma, se conspiraba contra la existencia del propio Estado. Y ésta es -afirmémoslo- la principal razón que nos ofrece. Su cierre estaba legitimado, pues, no por su manifiesto anticatolicismo, sino por su anarquismo. Y al proponer dicho motivo puso de relieve uno de los fundamentos de toda educación: el de organizar y legitimar el Estado y sus instituciones. Para Unamuno, debe darse un círculo perfecto entre el Estado y la educación, que podríamos cristalizar en las siguientes proposiciones, con las cuales hemos iniciado el presente apartado: el Estado debe organizar y legitimar la educación como la educación al propio Estado. La correlación, en términos organizativos, debe ser perfecta. Y aquí no hablamos, aunque pudiéramos, de la importancia que la educación tiene en la estructuración profesional e institucional de las sociedades y, por ende, de los Estados, con la cual concuerda Unamuno, hablamos tan sólo de que la educación no debe oponerse a la existencia del propio Estado, ya que la educación debe estar al servicio del Estado como el Estado de la

70 Cf., Unamuno, Miguel: «Confesión de culpa», en O. C., Madrid, Escelicer, 1970, vol. 8, pp. 398 y 400 .

Cf., Unamuno, Miguel: «Confesión de culpa», en o. C., Madrid, Escelicer, 1970, vol. 8, pp. 398-399.

Cf., Unamuno, Miguel: «Confesión de culpa», en o. C., Madrid, Escelicer, 1970, vol. 8, p. 339.

Cf., Unamuno, Miguel: "Confesión de culpa», en o. C., Madrid, Escelicer, 1970, vol. 8, p. 339.

74 Cf., Carta de Unamuno a Casimiro González Trilla, Salamanca, I2.XI.1909, Unamuno, Miguel: Epistolario Americano (I890-1939), Salamanca, Ediciones Universidad de Salamanca, 1996, pp. 337-338. 
UNAMUNO: LAS FUNCIONES EDUCATIVAS DEL ESTADO. DEL ESTADO DOCENTE AL ESTADO ORGANIZADOR DE LA ENSEÑANZA EMANUEL JOSÉ MAROCO DOS SANTOS

educación. Sobre lo que Unamuno nunca se pronunció fue sobre cómo concebir este círculo entre el Estado y la educación, cuando aquél es dictatorial.

Es imposible resistir a las solicitaciones del ambiente. Tenía ya la pluma en la mano para deciros algo de la ridícula agitación en contra de España que provocó entre la badulaquería internacional el fusilamiento del desdichado Ferrer, de quien ha querido hacerse poco menos que un genio, del cierre de las escuelas por él creadas, y que se cerraron, no por anticatólicas, sino por anarquistas, por conspirarse en ellas contra la existencia del Estado -aparte de que, como escuelas, eran detestables; focos de fanatismo, superstición e ignorancia-, de la brutal ignorancia que respecto a las cosas de España reina en el extranjero y singularmente en Francia, de... ${ }^{75}$.

En definitiva, para el último Unamuno, es decir, para el Unamuno posterior a 1931, el Estado debería ser el único órgano con el poder de organizar la enseñanza. Con esta toma de posición, Unamuno cambió de opinión, ya que hasta dicha fecha Unamuno fue un acérrimo defensor del Estado docente, ideal que pululaba con vigor en el ambiente intelectual de la época. Con ello, no afirmamos que Unamuno haya propuesto, menos conceptualizado, el Estado Organizador de la Enseñanza. Lo que afirmamos es que a partir de su regreso del exilio, a raíz de su oposición al artículo $48 .^{\circ}$ de la Constitución de la República Española de I93I, Unamuno abandonó su concepción de Estado docente al criticar la escuela única, y que, al hacerlo, se dirigió a una concepción del Estado en cuanto entidad organizadora de la enseñanza. Fue a la luz de este cambio teórico que hemos analizado la propuesta unamuniana de derogación de los artículos $295 .^{\circ}$ y $296 .^{\circ}$ de la Ley de Instrucción Pública de g de septiembre de 1857, así como del artículo 2. ${ }^{\circ}$ del Concordato de I85I, pese al hecho de que la misma fuese simultánea con su concepción del Estado docente. Y la hemos analizado -decíamos-, porque dicha lectura la permite la propia orgánica de su pensamiento que arranca de la afirmación de Bunge, «no es posible organizar el Estado sino por medio de la educación; no es posible organizar la educación sino por medio del Estado». Cabría subrayar, tan sólo, que, para Unamuno, de la misma forma que la enseñanza debería ser organizada y legitimada por el Estado así también el Estado debería ser organizado y legitimado por la propia enseñanza. Por ello, no dejó de criticar la Escuela Moderna de Francisco Ferrer, cuya labor docente iba en contra de los fundamentos del propio Estado.

\section{El Estado Mayor de la Enseñanza: una instancia legislativa superior e independiente al poder político}

Yo he pensado muchas veces, si acaso hubiese una reforma, que no podríamos llamar autonomía, pero que consistiera en ver si encontrábamos, o si se encontraba, una especie de Estado Mayor de la enseñanza, nombrado o elegido por sufragio del

75 Unamuno, Miguel: «El sentimiento de fortaleza», en o. C., Madrid, Escelicer, I966, vol. I, p. 335. 
profesorado de todos los grados, al cual se le encomendara, independientemente de este trasiego de Ministros que van y vienen, el preparar o presentar-si es que no se le daba confianza- una ley de Instrucción Pública donde se tuvieran en cuenta todas las experiencias de la práctica docente. Claro que esta especie de Estado Mayor no podría ser -no hace falta decirlo- el actual Consejo de Instrucción Pública, que es en gran parte, no sé si en todo, una hechura también ministerial. No; tendría que ser otra $\operatorname{cosa}^{76}$.

Si se tiene en consideración la conferencia Autonomía Docente, que Unamuno pronunció en la Real Academia de Jurisprudencia y Legislación de Madrid, el 3 de enero de 1917, percibimos que el Estado Mayor de la Enseñanza constituye una propuesta educativa unamuniana que, por sus sugerencias para el día de hoy, nos merece un análisis particular. Empero, antes de que empecemos su análisis y comentario, nos vemos obligados a afirmar que, más allá de que dicha propuesta sea muy significativa en lo que respecta (I) a la limitación del caprichoso y cambiante poder político y (2) a la posibilidad de ofrecer estabilidad y continuidad a los proyectos educativos, como lo subrayan y bien a nuestro juicio Delgado Criado $^{77}$ y Blanco Prieto ${ }^{78}$, la misma se halla apenas delineada por Unamuno en sus aspectos más elementales, lo que nos obliga a interpretarla tan sólo como una sugerencia. Y, en efecto, si preguntáramos cómo concibió Unamuno el Estado Mayor de la Enseñanza tendríamos algunas dificultades en determinar, cuanto a sus competencias, si éstas deberían circunscribirse al cuadro legal que estructura y organiza los varios grados de enseñanza o si deberían extenderse también a la determinación de las asignaturas y contenidos impartidos, y cuanto a sus miembros, si éstos deberían ser elegidos en igual proporción entre los varios grados de enseñanza o si deberían privilegiarse los profesores universitarios. Por ello, si hay algún rigor científico en el análisis y tratamiento de dicha propuesta unamuniana, sus comentaristas estarían obligados a afirmar que Unamuno no respondió a estas ni a otras cuestiones fundamentales para su inmediata concreción. Sin embargo, y no obstante la forma genérica como Unamuno la planteó, creemos que ésta merece ser analizada, ya que su concreción podría minimizar los efectos desastrosos del constante cambio de políticas educativas tanto más cuanto los pueblos hispánicos, como lo percibe con mucho acierto Unamuno, son tendenciosamente individualistas, desprovistos de conciencia colectiva y, por ello, sujetos a arranques individualistas.

El diagnóstico unamuniano acerca de las competencias del Ministerio de Instrucción Pública era profundamente negativo. Si se analizan los textos en que se detuvo sobre el tema, verificamos que, a su juicio, dicho ministerio era el «pariente

${ }_{76}$ Unamuno, Miguel: Autonomía Docente. Conferencia pronunciada en la sesión pública de 3 de enero de I9I7, en la Real Academia de Jurisprudencia y Legislación, de Madrid, en o. C., Madrid, Escelicer, 197I, vol. 9, p. 35I.

77 Cf., Delgado Criado, Buenaventura: Unamuno educador, Madrid, Editorial Magisterio Español, 1973, p. 22I.

78 Cf., Blanco Prieto, Francisco: Unamuno, profesor y rector en la Universidad de Salamanca, Salamanca, Hergar Ediciones Antema, 20II, p. 6II. 
UNAMUNO: LAS FUNCIONES EDUCATIVAS DEL ESTADO. DEL ESTADO DOCENTE

AL ESTADO ORGANIZADOR DE LA ENSEÑNAZA

EMANUEL JOSÉ MAROCO DOS SANTOS

pobre» de los sucesivos gobiernos, como lo comprobaba el hecho de que sus ministros lo considerasen como un «trampolín» para otros de mayor categoría ${ }^{79}$. A dicho hecho, que de por sí pone bien de relieve la flaca, diríamos flaquísima, importancia que se concedía, por aquel entonces, a la educación, se sumaba el hecho de que no había políticas educativas ${ }^{80}$; y cuando las había, éstas no eran más que deseos partidarios ideológicamente tendenciosos ${ }^{81}$. Por otro lado, a la ausencia de verdaderas políticas educativas, se juntaba también el problema de la legislación, ya que, según Unamuno, como lo subraya Gómez Molleda, la Ley Moyano era una ley muy poco adaptada a las exigencias educativas finiseculares, siendo por ello necesario reformarla ${ }^{82}$. Empero, nadie se proponía hacerlo, ni en el sentido conservador ni en el liberal, por miedo a una guerra civi ${ }^{8_{3}} \mathrm{o}$ por los trastornos y molestias que suscitaría entre los padres y profesores ${ }^{84}$; y cuando se intentaba, se hacía mal ${ }^{85}$.

De lo demás, de ese tejer y destejer desde el ministerio la tela de Penélope de nuestra enseñanza oficial, nadie hace caso. Cada ministro trae su receta, cambia las etiquetas de los frascos y el lugar de la colocación de algunos, y sólo consigue que, confundiéndose los que despachan en la droguería, hagan una barbaridad ${ }^{86}$.

Para combatir estos problemas, Unamuno propuso la creación del Estado Mayor de la Enseñanza que, a partir de la información contenida en la conferencia Autonomía Docente, de igi7, único texto en que Unamuno se refiere a dicha propuesta, debería ser un órgano extraordinario, nombrado por el sufragio de todos los profesores de todos los grados de enseñanza que, independiente de las políticas del Gobierno, formase una ley de instrucción pública que tuviese en cuenta toda práctica docente. Si es cierto que Unamuno no lo afirmó, creemos, por lo que nos sugiere la forma como analiza el tema a lo largo de su producción

79 Cf., Unamuno, Miguel: Autonomía Docente. Conferencia pronunciada en la sesión pública de 3 de enero de I9I7, en la Real Academia de Jurisprudencia y Legislación, de Madrid, en O. C., Madrid, Escelicer, I971, vol. 9, pp. 346-347.

so Cf., Unamuno, Miguel: Autonomía Docente. Conferencia pronunciada en la sesión pública de 3 de enero de I9I7, en la Real Academia de Jurisprudencia y Legislación, de Madrid, en O. C., Madrid, Escelicer, 197I, vol. 9, p. 347.

${ }_{81}$ Cf., Unamuno, Miguel: «Recuerdo de don Francisco Giner», en o. C., Madrid, Escelicer, I968, vol. 3, p. II8I.

82 Cf., Gómez Molleda, María Dolores: «Unamuno, rector regeneracionista», Revista de Educación, Madrid, n. ${ }^{\circ}$ extra (1997), p. I44.

${ }_{3} C f$., Unamuno, Miguel: Autonomía Docente. Conferencia pronunciada en la sesión pública de 3 de enero de I9I7, en la Real Academia de Jurisprudencia y Legislación, de Madrid, en O. C., Madrid, Escelicer, 1971, vol. 9, p. 347.

${ }_{4}$ Cf., Unamuno, Miguel: La enseñanza del latín en España, en O. C., Madrid, Escelicer, 1966, vol. I, p. 875 .

${ }_{85}$ Cf., Unamuno, Miguel: Autonomía Docente. Conferencia pronunciada en la sesión pública de 3 de enero de I9I7, en la Real Academia de Jurisprudencia y Legislación, de Madrid, en o. C., Madrid, Escelicer, 1971, vol. 9, p. 347.

${ }_{86}$ Unamuno, Miguel: De la enseñanza superior en España, en O. C., Madrid, Escelicer, I966, vol. I, p. 752 . 
ensayística, que dicho órgano podría también tener competencia legal para decidir sobre las políticas educativas, de tal modo que las mismas no estuviesen sujetas ni a las orientaciones ideológicas de los partidos políticos, de talante conservador o liberal, ni tampoco al capricho de los sucesivos ministros de Educación. Sin que deseemos minimizar el significado de dicha propuesta, creemos que la génesis de la misma radica en su destitución como rector de la Universidad de Salamanca, en el año de I9I4, por motivos ministeriales nunca públicamente divulgados. Por lo demás, es la propia carta que Unamuno, en conjunto con Luis Maldonado y Pedro Urbano de la Calle, ha enviado al, por aquel entonces, ministro de Instrucción Pública, el is de septiembre de i9i4, la que lo atestigua, ya que la misma pone de relieve la desconfianza que el bilbaíno sentía con respecto a los políticos y a la política finisecular española ${ }^{87}$.

Ni las Ciencias, ni las Letras, ni las Artes son monárquicas o republicanas. La cultura está por encima y por debajo de las pequeñas diferencias contingentes, accidentales y temporales de las formas de Gobierno ${ }^{88}$.

Para cerrar este apartado quisiéramos valorar esta propuesta unamuniana concerniente a la creación del Estado Mayor de la Enseñanza. Por de pronto, lo que se nos ocurre afirmar es que dicha propuesta tiene el enorme mérito de evitar la partidización y el permanente cambio de las políticas educativas, ya que favorece la formación de una política educativa independiente de las ideologías partidarias, de talante conservador o liberal. Y, por otro lado, tiene también la enorme virtud de vincular a todos los agentes educativos en la construcción de una política educativa común y de un sistema legislativo más apropiado a las necesidades de cada época histórica. Lo que Unamuno no definió fue las nuevas funciones del ministro y del Ministerio de Instrucción Pública, ya que tal y como Unamuno concibe su Estado Mayor de la Enseñanza aquéllos pierden gran parte de sus funciones. Sin embargo, la idea de la creación de una instancia superior al ministro y al Ministerio de Instrucción Pública capaz de imponer neutralidad ideológica y permanencia de las reformas educativas nos parece muy acertada y llena de significado, tanto más cuanto que nuestros pueblos ibéricos, hondamente carentes de conciencia colectiva común, tienden a esperar una solución individualista (el héroe carlyliano) para los problemas políticos, sociales, económicos y educativos del país. Lo que nunca se nos ocurre pensar en nuestros pueblos es que de las sinergias y de los esfuerzos conjuntos de todos pueda salir un nuevo rumbo para los problemas nacionales. Por ello, la propuesta de Unamuno tiene un enorme mérito, ya que hace depender la organización de la enseñanza no de un individuo o conjunto de individuos intelectualmente subordinados a una determinada

87 Cf., Carta de Unamuno, Luis Maldonado y Pedro Urbano de la Calle al Ministro de Instrucción Pública, Salamanca, I5.IX.I9I4, Archivo CMU, texto manuscrito.

88 Unamuno, Miguel: Discurso en el Paraninfo de la Universidad de Salamanca el día I de octubre de I93I, al inangurar, como rector de ella, el curso académico de 1931-32, en O. C., Madrid, Escelicer, 1971, vol. 9, p. 396. 
UNAMUNO: LAS FUNCIONES EDUCATIVAS DEL ESTADO. DEL ESTADO DOCENTE

AL ESTADO ORGANIZADOR DE LA ENSEÑNAZA

EMANUEL JOSÉ MAROCO DOS SANTOS

ideología política, sino de todos los agentes implicados en el acto educativo. Cabría tan sólo afirmar que Unamuno, al pretender la reforma de la Ley Moyano, pretendía romper con un documento que, como lo subraya Barros Dias, conseguía un razonable equilibrio ideológico entre conservadores y liberales en torno al problema de la enseñanza ${ }^{8}$. De hecho, basta no pasar por alto las propuestas educativas de Unamuno relacionadas con el Estado docente y con la derogación de los artículos 295. ${ }^{\circ}$ y $2966^{\circ}$ de la Ley de Instrucción Pública de o de septiembre de I857 así como del artículo 2. ${ }^{\circ}$ del Concordato de I85I para percibir que Unamuno adopta un posicionamiento señaladamente liberal en lo que concierne al tema educativo, por lo menos, en cuanto a la organización de la enseñanza, porque otra es, como es bien sabido, su posición con respecto a la «autonomía» económica de las universidades.

En definitiva, en el año de 1917, Unamuno propuso, en su conferencia Autonomía docente, la creación de lo que sugestivamente denominó Estado Mayor de la Enseñanza. Para el, por aquel entonces, destituido rector de la Universidad de Salamanca, urgía limitar los efectos desastrosos a nivel educativo del caprichoso y cambiante poder político. Por ello, propuso la formación de un órgano extraordinario, nombrado por sufragio de todos los profesores de todos los grados de enseñanza, que fuese capaz de formar una ley de instrucción pública, que sustituyese la antigua Ley Moyano, y que, a partir de la práctica docente, estuviese más adaptada a las nuevas exigencias educativas y sociales de principios del siglo xx. Si es cierto que Unamuno no lo propuso -subrayémoslo-, creemos que dicho órgano, por su independencia ideológica y por su representatividad, podría tener, también, la función de determinar los contenidos y las asignaturas de los dos primeros grados de enseñanza, lo que sería de gran utilidad para los días de hoy, ya que actualmente se añaden y restan asignaturas al gusto individual de cada ministro de Educación.

\section{Conclusiones}

Revisitar a Unamuno, sus planteamientos y propuestas, tiene la enorme virtud de que nos acerquemos a los mayores problemas de lo humano y, en este caso concreto, a los mayores problemas políticos con los cuales se enfrenta una educación libre y desinteresada.

Intentar concretar la igualdad de oportunidades educativas, entre sexos y estratos sociales, fue un reto de su época histórica como lo es de la nuestra, así como lo fue y es también la búsqueda de la libertad ideológica. Saber cómo concretar dichos ideales es donde se separan los que piensan y teorizan sobre la educación.

89 Cf., Barros Días, José Manuel: Miguel de Unamuno e Teixeira de Pascoaes: compromissos plenos para a educação dos povos peninsulares, Lisboa, Imprensa Nacional Casa da Moeda, vol. 2, 2002, p. 34 . 
Para Unamuno, en cuanto hijo natural de su época histórica, la solución para el primer problema, el de la igualdad de oportunidades educativas, pasaba por la democratización de la enseñanza, y la del segundo por la afirmación y negación de la escuela única en el antes y después de i93i.

Saber si la igualdad de oportunidades educativas se cumple con la democratización de la enseñanza es un problema que deberemos plantear hoy, ya que no es creíble que una escuela pública de provincia ofrezca la misma calidad educativa que un colegio privado de élites de una gran metrópoli. Y en esto se juega, como es obvio, mucho más que una mera adhesión ideológica.

En cuanto a la libertad ideológica, ésta tampoco deja de plantear problemas teóricos, ya que hoy como ayer se escinden opiniones sobre lo que deberíamos buscar: si un Estado docente, si un Estado organizador de la enseñanza. Unamuno, uno de los mayores intelectuales españoles de todos los tiempos, tuvo dificultades en responder a dicha pregunta, terminando por postular alternadamente las dos opciones. Pero su dificultad en mantenerse en la misma posición no debe señalar su debilidad como intelectual, sino su entero compromiso con la verdad y con lo humano.

Mucho tenemos, todavía hoy, que debatir y plantear. No para que encontremos soluciones definitivas para dichos problemas, sino más bien para que nos acerquemos poco a poco a la eterna esencia de las cosas. Se juega mucho en la educación, todos lo sabemos, como sabemos también que, por desgracia, lo que más se juega en ella son intereses de poder. Pocos intelectuales han tenido un espíritu tan noble como el de Unamuno como para sostener una posición opuesta a la que sostenía en nombre de la libertad. ¿Y no es éste uno de los mayores ideales humanos? ¿No es la libertad la finalidad de la educación? He aquí la razón por la que me causa tanta simpatía su concepción de Estado Mayor de Enseñanza. La ética es la base de la política y ésta de la educación. ¿Cómo puede haber, pues, buenas propuestas educativas si la política, en base a sus juegos de poder, se realiza fuera del ámbito ético?

El insigne Unamuno despreciaba las soluciones concretas. Y creo que todos los espíritus nobles las desprecian. Vivir escépticamente, con dudas cuanto a lo logrado, es la base de un futuro mejor. Tal vez por ello nos guste tanto Unamuno.

\section{Bibliografía}

FUENTES

Concordato de I8sI.

Constitución de la República Española de 193 I.

Ley de Instrucción Pública de g de septiembre de I857.

Unamuno, Miguel: Carta de Unamuno, Luis Maldonado y Pedro Urbano de la Calle al Ministro de Instrucción Pública, Salamanca, I5.IX.I9I4, Archivo CMU, texto manuscrito.

Unamuno, Miguel: «L'instruction publique en Espagne», Études Diplomatiques, Paris (may. 19I4). Archivo CMU.

Unamuno, Miguel: «Pedagogía castrense», El Mercantil Valenciano, 04.viI.I922, Archivo CMu. Unamuno, Miguel: Obras Completas, Madrid, Escelicer, 9 vols., 1967-197I. 
UNAMUNO: LAS FUNCIONES EDUCATIVAS DEL ESTADO. DEL ESTADO DOCENTE

AL ESTADO ORGANIZADOR DE LA ENSEÑNAZA

EMANUEL JOSÉ MAROCO DOS SANTOS

Unamuno, Miguel: Epistolario Americano (1890-1939), Salamanca, Ediciones Universidad de Salamanca, 1996.

\section{BibLIOGRAFÍA SECUNDARIA}

Aguilera, César: «Pensamiento educacional de D. Miguel de Unamuno», Calasancia, vol. II, n. ${ }^{\circ} 44$ (oct.-dic. 1965), pp. 405-523.

Barros Dias, José M.: Miguel de Unamuno e Teixeira de Pascoaes: compromissos plenos para a educação dos povos peninsulares, Lisboa, Imprensa Nacional Casa da Moeda, vol. 2, 2002.

Blanco Prieto, Francisco: Unamuno, profesor y rector en la Universidad de Salamanca, Salamanca, Hergar Ediciones Antema, 2oII.

Cardwell, Richard A.: «Miguel/Mijail: La (dia) lógica de Amor y pedagogía», en Flórez MiGuel, Cirilo (coord.): Tu mano es mi destino, Col. Biblioteca Unamuno, n. ${ }^{\circ} 22$, Salamanca, Ediciones Universidad de Salamanca, 2000, pp. 47-58.

Cifo González, Manuel: «Amor y pedagogía o el problema de la educación visto por Miguel de Unamuno", en Chaguaceda Toledano, Ana (ed.): Miguel de Unamuno. Estudios sobre su obra. II, Col. Biblioteca Unamuno, n. ${ }^{\circ} 28$, Salamanca, Ediciones Universidad de Salamanca, 2005, pp. 329-347.

Cruz Hernández, Miguel: «La misión socrática de Unamuno», Cuadernos de la Cátedra Miguel de Unamuno, vol. 3 (1952), pp. 4I-53.

Delgado Criado, Buenaventura: Unamuno educador, Madrid, Editorial Magisterio Español, 1973.

Espino GutiérRez, Gabriel: «El maestro Fray Luis de León y el maestro Unamuno», Boletín de la Universidad Compostelana, fasc. 2, n. ${ }^{\circ}$ 73-74 (1965-1966), pp. I07-II7.

Flórez, Ramiro: «Sistema de pensamiento y razón educativa en Unamuno», Cuadernos Hispanoamericanos, n. ${ }^{\circ}$ 440-44I (1987), pp. I87-204.

Forgione, José D.: Miguel de Unamuno: sus ideas pedagógicas. Unamuno y la Universidad de Salamanca, Buenos Aires, Imp. Asiática, 1920.

Frayle Delgado, Luis: "La dialéctica del eros en “Amor y pedagogía”", Azafea, n. 3 (1990), pp. $265-283$.

García Blanco, Manuel: «Amor y pedagogía, nívola unamuniana», La Torre, año 9, n. ${ }^{\circ}$ 35-36 (jul.-dic. 196I), pp. 443-478.

GiL, Miguel L.: «La educación como materia novelesca. Paul Bourget - Unamuno - Pérez de Ayala», Cuadernos Hispanoamericanos, n. ${ }^{\circ} 348$ (jun. 1979), pp. 596-608.

Gómez DE LA Torre, Ignacio B.: «Unamuno y la Universidad: rector e intelectual», en FlóRez Miguel, Cirilo (coord.): Tu mano es mi destino, Col. Biblioteca Unamuno, n. ${ }^{\circ} 2$, Salamanca, Ediciones Universidad de Salamanca, 2000, pp. 47-58.

Gómez Molleda, María D.: "Unamuno, rector regeneracionista», Revista de Educación, n. ${ }^{\circ}$ extra (1997), pp. I37-I47.

Herrero Castro, Santos: «Pensamiento socio-educativo de Miguel de Unamuno: estructura y cambio social en la España del primer tercio del siglo xx», Studia Paedagogia, Salamanca, n. 22 (I99I), pp. 55-79.

Madruga Méndez, Joaquín: Miguel de Unamuno: profesor y político, Salamanca, Gráficas Cervantes, 2007.

Moralejo Laso, Abelardo: «Don Miguel de Unamuno profesor de griego y de historia de la lengua castellana: impresiones y recuerdos de un alumno", en AA. vv.: Homenaje al Prof. Alarcos, Valladolid, Universidad de Valladolid, vol. 2, 1966, pp. 329-352.

Morasverdes, El Chico de (pseudónimo): «Páginas pedagógicas. Unamuno catedrático», La Iberia. Semanario Independiente, año 4, n. ${ }^{\circ}$ I59 (05.V.I906), p. 4.

Morón Arroyo, Ciriaco: Hacia el sistema de Unamuno: estudios sobre su pensamiento y creación literaria, Col. Referencias, n. ${ }^{\circ}$ 2, Palencia, Cálamo, 2003. 
Raut, François: "Mi defensa" o el borrador de una contestación inédita a la tentativa de destitución de Unamuno del rectorado de Salamanca por el obispo Cámara (finales de 1903 - principios de 1904)», Cuadernos de la Cátedra Miguel de Unamuno, Salamanca, vol. 39 (2004), pp. 13-25.

Roberts, Stephen: Miguel de Unamuno o la creación del intelectual español moderno, Col. Biblioteca Unamuno, n. ${ }^{\circ}$ 33, Salamanca, Ediciones Universidad de Salamanca, 2007.

Rubio Latorre, Rafael: «Unamuno educador», Cuadernos de la Cátedra Miguel de Unamuno, vol. 23 (1973), pp. 27-47.

Turin, Yvonne: Miguel de Unamuno Universitaire, Paris, SEvpen, 1982.

VAldés, Mario J.: «"Amor y pedagogía” y lo grotesco», Cuadernos de la Cátedra Mignel de Unamuno, vol. I3 (1963), pp. 53-62. 